\title{
INFLUÊNCIA DO MANGANÊS NO CRESCIMENTO E NA COMPOSIÇÃO MINERAL DE MUDAS DE CARAMBOLEIRA ${ }^{1}$
}

\author{
AMANDA HERNANDES ${ }^{2}$, WILLIAM NATALE ${ }^{3}$, JAIRO OSVALDO CAZETTA ${ }^{4}$, \\ DANILO EDUARDO ROZANE², HENRIQUE ANTUNES DE SOUZA², \\ LILIANE MARIA ROMUALDO²
}

\begin{abstract}
RESUMO - A carambola apresenta boas perspectivas de comercialização, devido ao crescente aumento na demanda por frutas, tanto no mercado interno como no externo, sendo uma opção promissora de cultivo. Porém, as principais áreas de produção de carambola estão localizadas em regiões caracterizadas por solos ácidos, com baixa saturação por bases e, frequentemente, possuem alumínio e manganês em quantidades suficientemente altas para limitar o desenvolvimento normal dos vegetais em geral. O objetivo deste trabalho foi avaliar os efeitos do manganês no crescimento e na composição química da caramboleira, assim como na massa seca das plantas. O delineamento experimental adotado foi o de blocos casualizados, constituídos de 4 doses de $\mathrm{Mn}\left(0 ; 0,5 ; 25\right.$ e $50 \mathrm{mg} \mathrm{L}^{-1}$ de Mn), 4 épocas de coleta (30; 60; 90 e 120 dias após o emprego das doses de Mn) e 3 repetições, em mudas conduzidas em solução nutritiva. Foram avaliados tanto aspectos biológicos como nutricionais das mudas de caramboleira, a fim de identificar a dose mais adequada de $\mathrm{Mn}$ e seus efeitos no crescimento dessa frutífera. As doses de Mn e as épocas de coleta influenciaram nos teores e no acúmulo de $\mathrm{Mn}$, assim como a massa seca, em função do órgão analisado. Ocorreu aumento linear nos teores e acúmulos de $\mathrm{Mn}$ com o incremento das doses de manganês em todas as estruturas. Houve aumento na eficiência de absorção de Mn com o incremento das doses, entretanto diminuição na eficiência de transporte e utilização do Mn. Os parâmetros biológicos avaliados apresentaram as maiores médias na concentração de $0,5 \mathrm{mg} \mathrm{L}^{-1}$ de $\mathrm{Mn}$.
\end{abstract}

Termos para indexação: Averrhoa carambola, frutífera, micronutriente, Mn.

\section{INFLUENCE OF MANGANESE ON GROWTH AND IN THE MINERAL COMPOSITION OF STAR FRUIT TREE SEEDLINGS}

\begin{abstract}
The star fruit presents good prospects of commercialization, due to the increasing demand for fruit, both in internal and external markets, being a promising option of cultivation. However, the main areas of star fruit production are located in regions characterized by acid soils, with low base saturation and often have aluminum and manganese in quantities high enough to limit the normal development of plants in general. The objective of this work was to evaluate the effects of manganese on growth and in the chemical composition of star fruit tree, as well as the dry mass of plants. The experimental design was a randomized block, consisted of 4 levels of Mn (0, 0.5, 25 and $\left.50 \mathrm{mg} \mathrm{Mn} \mathrm{L}^{-1}\right), 4$ times of collection (30, 60, 90 and 120 days of placement of the levels of $\mathrm{Mn}$ ) and 3 replications, on seedlings conducted in nutrient solution. Biological and nutritional aspects of star fruit seedlings to identify the most appropriate level of $\mathrm{Mn}$ and its effects on growth of this fruit tree were evaluated. The levels of $\mathrm{Mn}$ and times of collection influenced the contents and the accumulation of $\mathrm{Mn}$, as well as the dry mass depending of the organ examined. There was a linear increase in the levels and accumulation of $\mathrm{Mn}$ as a function of increasing levels of manganese in all structures. There was an increase in the efficiency of the absorption of Mn with the increasing of the levels, however, decrease the efficiency of the transportation and the use of Mn. The biological parameters evaluated showed the highest average in the concentration of $0.5 \mathrm{mg} \mathrm{L}^{-1} \mathrm{Mn}$.
\end{abstract}

Index terms: Averrhoa carambola, fruit tree, micronutrients, Mn.

\footnotetext{
1(Trabalho 234-09). Recebido em: 13-10-2009. Aceito para publicação em 25-01-2010. Parte da dissertação de Mestrado do primeiro autor apresentada ao curso de Pós-graduação em Agronomia-ciência do solo, FCAV/Unesp.

${ }^{2}$ Pós-graduandos, Departamento de Solos e Adubos, Universidade Estadual Paulista, Faculdade de Ciências Agrárias e Veterinárias (FCAV/Unesp). Fone/Fax (16) 32092672. Via de Acesso Prof. Paulo Donato Castellane, s/n. 14870-000 Jaboticabal-SP. E-mail: amahernandes@hotmail.com; danilorozane@yahoo.com.br; henrique.antuness@yahoo.com.br; lilianeromualdo@yahoo.com.br ${ }^{3}$ Professor Adjunto, Depto. de Solos e Adubos, FCAV/Unesp. Bolsista PQ do CNPq. E-mail: natale@fcav.unesp.br ${ }^{4}$ Professor Adjunto, Depto. de Tecnologia, FCAV/Unesp. E-mail: cazetta@fcav.unesp.br
} 


\section{INTRODUÇÃO}

A caramboleira é considerada fruteira de grande potencial mercadológico devido, entre outros fatores, ao rápido desenvolvimento, alta produtividade e frutos com sabor e aparência peculiares (SAÚCO, 1994). O Estado de São Paulo é o principal produtor de carambola, destacandose as regiões de Mirandópolis e de Jaboticabal, que apresentam a maior produção e a maior área de cultivo de caramboleiras, respectivamente. Porém, as principais áreas de produção agrícola estão localizadas em regiões caracterizadas por solos ácidos, com baixa saturação por bases e, frequentemente, possuem alumínio e manganês em quantidades suficientemente altas (PRADO; NATALE, 2008), limitando o desenvolvimento normal dos vegetais em geral.

$\mathrm{Na}$ presença de quantidades excessivas das formas trocável ou solúvel de Mn no meio de crescimento, os tecidos vegetais apresentarão, também, elevados teores desse nutriente, podendo atingir níveis tóxicos, visto que as plantas absorvem e transportam o elemento em quantidades elevadas, resultando em acúmulo nas folhas e produzindo sintomas bem definidos (FOY, 1973; PAVAN; BINGHAM, 1981).

Concentrações tóxicas de Mn no solo podem ser neutralizadas através da calagem que, elevando o $\mathrm{pH}$, precipita o excesso de Mn disponível, o que reduz sua absorção pelas plantas (MALAVOLTA; KLIEMANN, 1985). Além de elevar o pH, a calagem proporciona incremento na concentração de cálcio na zona radicular, podendo reduzir a absorção e, consequentemente, o efeito tóxico do manganês, em decorrência da competição pelo mesmo sítio de absorção (FOY, 1973; MALAVOLTA et al., 1997).

O efeito prejudicial do excesso de Mn é difícil de ser estudado isoladamente, visto que esse nutriente interage com outros elementos, como, por exemplo, o ferro, cuja deficiência é induzida na presença de alta concentração de Mn no solo (LEE, 1972). Na literatura, existem relatos de teores de $\mathrm{Mn}$ em folhas de caramboleira variando de 73 a $1.745 \mathrm{mg} \mathrm{kg}^{-1}$ (SILVA et al., 1984; CRANE, 1998; PRADO, 2003; LEAL, 2006). Essa variação pode ser devida às diferenças na amostragem, visto que folhas mais velhas apresentam maiores teores de Mn que folhas jovens ou, ainda, devido à diferença entre cultivares, idade das plantas, manejo, entre outras possíveis variáveis.

É importante ressaltar que esses teores foliares de Mn encontrados em caramboleiras são considerados muito altos, quando comparados com outros micronutrientes e, também, com o manganês em outras frutíferas, os quais se aproximam e até ultrapassam os teores de macronutrientes, como o $\mathrm{P}$ e o S. Isso evidencia a necessidade de pesquisas objetivando avaliar a importância do Mn para a caramboleira, a fim de elucidar se a alta quantidade desse elemento presente na planta desempenha alguma função específica na caramboleira, ou se essa frutífera apresenta consumo de luxo, tolerando altas concentrações do elemento em seus tecidos.

Tendo em vista a escassez de informações sobre a nutrição da caramboleira, principalmente em relação aos micronutrientes, torna-se importante a avaliação dos efeitos do manganês no crescimento e na composição química dessa frutífera, bem como na produção de massa seca.

\section{MATERIAL E MÉTODOS}

O experimento foi realizado em casa de vegetação, no período de outubro/2008 a março/2009, na FCAV/Unesp, Câmpus Jaboticabal, em JaboticabalSP, com coordenadas geográficas de $21^{\circ} 15^{\prime} \mathrm{S}$ de latitude e $48^{\circ} 18^{\prime} \mathrm{W}$ de longitude, e altitude de 575 metros.

A frutífera estudada foi a caramboleira (Averrhoa carambola), cv. BR96, enxertada sobre porta-enxertos obtidos por semente. O delineamento experimental adotado foi o de blocos casualizados, com 3 repetições, em esquema fatorial $4 \times 4$, empregando-se 4 doses de Mn e 4 épocas de coleta das plantas ao longo do período de estudo, num total de 48 parcelas. Cada unidade experimental (vaso de $5,5 \mathrm{~L}$ ) recebeu 2 mudas de caramboleira, enxertadas há um ano. As plantas foram submetidas à aplicação de doses de $\mathrm{Mn}$, na forma de $\mathrm{MnSO}_{4}$, sendo $\mathrm{D}_{0}=$ zero; $\mathrm{D}_{1}=0,5 ; \mathrm{D}_{2}=25$ e $\mathrm{D}_{3}=50 \mathrm{mg} \mathrm{L}^{-1}$ de $\mathrm{Mn}$. $\mathrm{D}_{1}$ foi considerada a dose-padrão, de acordo com a concentração de Mn contida na solução nutritiva de Furlani (1999) e recomendada por Rozane et al. (2007), como a mais adequada para a condução de mudas de caramboleira. As doses $\mathrm{D}_{2}$ e $\mathrm{D}_{3}$ foram estabelecidas a partir de ensaios preliminares, em que foram testadas doses crescentes de manganês, em solução nutritiva, cultivando-se mudas de caramboleiras até que as plantas apresentassem efeitos visuais de excesso de Mn. As coletas para análises foram realizadas aos 30; 60; 90 e 120 dias após a aplicação dos tratamentos.

Antes da aplicação dos tratamentos, durante os primeiros 15 dias de adaptação, as mudas foram mantidas em solução nutritiva completa de Furlani (1999), diluída a 1/4 da concentração usual. Após esse período, as plantas foram submetidas à solução nutritiva completa, com exceção do Mn, sendo este 
empregado em diferentes doses, conforme as quantidades estabelecidas em cada tratamento.

Para o manejo da solução nutritiva ao longo do período de estudo, o $\mathrm{pH}$ foi monitorado em dias alternados, empregando-se um medidor portátil (PG 1400), ajustado a $5,0 \pm 0,5$, usando-se solução $\mathrm{NaOH}$ ou $\mathrm{HCl} 0,1 \mathrm{~mol} \mathrm{~L}^{-1}$. Na mesma ocasião, foi monitorada a condutividade elétrica da solução nutritiva, com o auxílio de um condutivímetro portátil (CG 220), mantendo-a com valor entre 2,0 e 2,4 dS m ${ }^{-1}$, já que não há indicação para mudas de caramboleira. A reposição da água evapotranspirada foi realizada com água destilada e deionizada. A solução nutritiva foi oxigenada durante todo o período diurno e renovada a cada 30 dias, até o final do experimento. O controle de pragas e doenças foi realizado durante todo o período experimental, conforme sua ocorrência.

O crescimento das plantas foi determinado a cada 30 dias, através da avaliação de parâmetros biológicos, como o diâmetro do caule do porta-enxerto, medido a $10 \mathrm{~cm}$ acima da base do caule; o diâmetro do caule do enxerto, determinado a $10 \mathrm{~cm}$ acima do ponto de enxertia; a altura das plantas; e a área foliar, avaliada com o auxílio de um aparelho integrador de áreas portátil LI-COR modelo LI-3100. Em cada coleta, as plantas foram divididas em folhas, caule e raízes. No laboratório, as estruturas foram lavadas, secas em estufa de circulação forçada de ar, com temperatura controlada $\left(65-70^{\circ} \mathrm{C}\right)$, até massa constante.

As diferentes partes da caramboleira foram pesadas e moídas, determinando-se os teores de macro e micronutrientes no tecido vegetal, seguindo a metodologia descrita por Bataglia et al. (1983).

A partir do teor de Mn no tecido vegetal (T) e da massa seca das plantas (MS), calculou-se o acúmulo de $\mathrm{Mn}(\mathrm{A})$ nos diferentes órgãos das mudas de caramboleiras, ao longo do período experimental, pela fórmula: $\mathrm{A}\left(\mu \mathrm{g}_{\text {planta }^{-1}}\right)=\mathrm{T} \times \mathrm{MS}$.

A partir da massa seca e do conteúdo de manganês na planta, foram calculados os índices: (a) eficiência de absorção = (conteúdo total do nutriente na planta)/(matéria seca de raízes), conforme Swiader et al. (1994); (b) eficiência de transporte = ((conteúdo do nutriente na parte aérea)/(conteúdo total do nutriente na planta)) x 100 , de acordo com Li et al. (1991); (c) eficiência de utilização = (matéria seca total produzida $)^{2} /$ (conteúdo total do nutriente na planta), segundo Siddiqi e Glass (1981).

Com os dados obtidos, foram realizadas análises de variância pelo teste $\mathrm{F}$ para os diversos parâmetros estudados. Para avaliar o efeito das doses de manganês e das épocas de coleta sobre as determinações na planta, foi utilizada a análise de regressão polinomial (ESTAT, 1992).

\section{RESULTADOS E DISCUSSÃO}

A aplicação de manganês promoveu diferenças significativas nos teores dos nutrientes determinados quimicamente, considerando-se todas as estruturas da planta. $\mathrm{O}$ acúmulo de $\mathrm{Mn}$ apresentou comportamento variável em função do órgão analisado, não apenas com a aplicação das doses de Mn, como também no decorrer das épocas de coleta.

Os teores de nutrientes encontrados nas folhas das caramboleiras $(\mathrm{N}=20-23 ; \mathrm{P}=15 ; \mathrm{K}=$ 20-23; $\mathrm{Ca}=6,4-6,9 ; \mathrm{Mg}=2,7-3,2 ; \mathrm{S}=2,1-2,3 \mathrm{~g}$ $\mathrm{kg}^{-1} ; \mathrm{e} \mathrm{B}=46-55 ; \mathrm{Cu}=2 ; \mathrm{Fe}=35-45 ; \mathrm{Zn}=27-30$ $\mathrm{mg} \mathrm{kg}{ }^{-1}$ ) estão, de maneira geral, dentro da faixa observada por Balerdi, citado por Crane et al. (1998), Silva et al. (1984), Prado (2003) e Leal (2006), em trabalho com a fruteira em condições de campo. Isso era esperado, visto que, com exceção do $\mathrm{Mn}$, os demais elementos foram fornecidos em quantidades consideradas adequadas para o normal crescimento e desenvolvimento das mudas de caramboleira, segundo Furlani (1999). Freitas (2008) e Rozane (2008), em experimento com mudas de caramboleiras em solução nutritiva de Furlani (1999), encontraram teores de nutrientes superiores, porém muito próximos, aos do presente estudo. As variações observadas podem ser devidas às diferenças nas cultivares, na idade das plantas, na amostragem do tecido e no tempo de cultivo.

Com o incremento das doses de manganês, os teores de $\mathrm{Mn}$ nas folhas, caule e raízes foram substancialmente aumentados, assim como seu acúmulo, o que era esperado (Tabela 1). Desdobrando-se as interações para doses, dentro de cada época de coleta, constatam-se incrementos lineares dos teores de manganês e de seu acúmulo (Tabela 2), independentemente da época de coleta e da estrutura avaliada. Na dose de $25 \mathrm{mg} \mathrm{L}^{-1}$ de $\mathrm{Mn}$, as folhas apresentaram teores cerca de 10 vezes maiores que na dose recomendada por Furlani (1999), igual a 0,5 mg L-1 de Mn. Já nas raízes, esse valor foi cerca de 18 vezes mais elevado. Na dose mais alta (50 $\mathrm{mg} \mathrm{L}^{-1}$ de $\left.\mathrm{Mn}\right)$, os teores chegaram a ser aproximadamente 20 vezes superiores àqueles observados na dose recomendada, tanto nas folhas como no caule e nas raízes. É importante ressaltar que os teores de Mn encontrados nas folhas, nas maiores doses, aproximaram-se, e até ultrapassaram valores de macronutrientes como o $\mathrm{P}$ e o $\mathrm{S}$. Observam-se, também, teores de manganês mais elevados no sistema radicular das mudas, em relação aos demais órgãos (Tabela 1), o que pode indicar algum mecanismo de defesa da planta ao excesso de Mn presente na solução nutritiva, não permitindo 
que a maior parte do elemento fosse transportada para a parte aérea.

O aumento na concentração de manganês na solução hidropônica conduziu a decréscimos nos teores de Fe nas folhas $\left(\mathrm{y}=45,71-0,3201 \mathrm{x} \mathrm{R}^{2}=\right.$ $\left.0,90^{* *}\right)$, caule $\left(\mathrm{y}=38,44-0,1294 \times \mathrm{R}^{2}=0,96^{* *}\right)$ e raízes $\left(\mathrm{y}=270,75-1,0165 \mathrm{x} \mathrm{R}^{2}=0,80^{* *}\right)$, e também em seu acúmulo, nas folhas $(\mathrm{y}=2.204,54$ $\left.8,384 \mathrm{x} \mathrm{R} \mathrm{R}^{2}=0,88^{* *}\right)$, caule $(\mathrm{y}=2.069,56-7,8421 \mathrm{x}$ $\left.\mathrm{R}^{2}=0,94^{* *}\right)$ e raízes $(\mathrm{y}=17.049,69-47,4590 \mathrm{x}$ $\left.\mathrm{R}^{2}=0,70^{* *}\right)$. Sintomas foliares de toxidez de manganês foram constatados nas folhas mais novas das caramboleiras, acompanhados de deficiência de Fe, caracterizada por clorose internerval com reticulado fino das nervuras $\mathrm{O}$ mesmo foi relatado por Salvador et al. (2003), trabalhando com doses de manganês em goiabeira. Esses dois nutrientes interagem em razão de uma inibição competitiva, na qual dois cátions bivalentes competem pelos mesmos sítios de absorção (FOY et al., 1978; MALAVOLTA et al., 1997), sendo a relação Fe/Mn muito utilizada como indicadora da toxidez de $\mathrm{Mn}$ em plantas (FOY, 1984). O Mn também é capaz de trocar com o Fe existente nos quelados, fazendo com que diminua sensivelmente a absorção de Fe pelas plantas (LUCENA et al., 1988).

No presente estudo, com o aumento das doses de manganês, ocorreu decréscimo na relação $\mathrm{Fe} / \mathrm{Mn}$ nas folhas $\left(\mathrm{y}=0,6362-0,0144 \mathrm{x} \mathrm{R}^{2}=\right.$ $0,79 * *)$, sendo que, para a dose-padrão $\left(0,5 \mathrm{mg} \mathrm{L}^{-1}\right.$ de $\mathrm{Mn}$ - FURLANI, 1999), a relação Fe/Mn foi de 0,55 . Abaixo dessa relação, constatou-se excesso de $\mathrm{Mn}$ nas folhas. Em decorrência, verificou-se aumento na relação $\mathrm{Mn} / \mathrm{Fe}$ nas folhas $(\mathrm{y}=0,2473+0,8277 \mathrm{x}$ $\left.\mathrm{R}^{2}=0,98^{* *}\right)$ a qual atingiu valores de $44 \mathrm{com}$ a aplicação da dose mais elevada de manganês $(50 \mathrm{mg}$ $\mathrm{L}^{-1}$ de $\mathrm{Mn}$ ), produzindo sintomas de toxidez de $\mathrm{Mne}$ deficiência de Fe. Veloso et al. (1995), trabalhando com doses de manganês em pimenteira, verificaram que a relação $\mathrm{Mn} / \mathrm{Fe}$ nos tecidos aumentou e que uma relação $\mathrm{Mn} / \mathrm{Fe}$ de 22 foi associada a sintomas severos de toxidez nas folhas das pimenteiras. Salvador et al. (2003) afirmam que, quando a relação $\mathrm{Mn} / \mathrm{Fe}$ for igual a 100 , podem ocorrer sintomas de deficiência de ferro e reduções nas concentrações foliares de cálcio e magnésio.

Nas plantas mantidas na ausência de manganês, constatou-se ataque de ácaro-branco e de antracnose. Esse fato não foi observado nas mudas dos tratamentos que receberam manganês via solução nutritiva, independentemente da dose. Isso pode ser devido ao papel do $\mathrm{Mn}$ no metabolismo vegetal, que atua como importante cofator de várias enzimaschave na biossíntese de metabólitos secundários da planta, associados à via do ácido chiquímico, incluindo aminoácidos aromáticos fenólicos, ligninas e flavonoides (BURNELL, 1988). Concentrações mais baixas desses compostos foram detectadas em tecidos deficientes em Mn de diversos vegetais, o que pode ser a causa da maior suscetibilidade a doenças das plantas carentes nesse nutriente (GRAHAM, 1983; MALAVOLTA, 2006). Outro fator a ser considerado é a participação do manganês na síntese da lignina, que enrijece os tecidos, aumentando a barreira física à entrada de patógenos (MALAVOLTA et al., 1997). Plantas capazes de mobilizar grandes quantidades de manganês, possivelmente tóxicas, para organismos patogênicos, podem afetar a patogenicidade de pragas e doenças (GRAHAM; WEBB, 1991). É importante salientar que, para evitar o comprometimento da presente pesquisa, foi realizado o controle químico, a partir do momento da detecção do ataque, cerca de 30 dias após o início do estudo.

Em condições de deficiência de manganês, as anormalidades observadas nas caramboleiras traduziram-se por clorose internerval nas folhas mais novas, palidez e início de formação reticulada grossa das nervuras. Os sintomas de toxidez foram visualizados no tratamento de $50 \mathrm{mg} \mathrm{L}^{-1}$ de $\mathrm{Mn}$, com salpicos adensados de minúsculas pontuações escuras por todo o limbo das folhas mais velhas. Nas folhas mais novas, ocorreu clorose internerval, com reticulado fino das nervuras, apresentando menor espessura laminar. As manchas escuras nas folhas mais velhas podem ter sido causadas pelo aumento na atividade da polifenoloxidase e, consequentemente, maior formação dos fenóis, ou dano na síntese de lignina, ou pela deposição de óxidos de manganês (MALAVOLTA; SANTOS, 1996). As alterações morfológicas visualizadas neste estudo, em função da deficiência ou toxidez de $\mathrm{Mn}$, corroboram relatos da literatura para diversos vegetais (MARSCHNER, 1995; VELOSO et al., 1995; MALAVOLTA et al. 1997; SALVADOR et al., 2003, EPSTEIN; BLOOM, 2006, DECHEN; NACHTIGALL, 2006).

A menor produção de massa seca na testemunha (Tabela 3 ), de modo geral, pode ser atribuída à diminuição na taxa de fotossíntese, que está diretamente relacionada ao teor de manganês na planta (LINDSAY; ROSS, 1988; MALAVOLTA et al., 1997). Desse modo, em condições de carência de $\mathrm{Mn}$, a produção será significativamente afetada. A deficiência de manganês prejudica a estrutura dos cloroplastos, afetando a fotossíntese, o que diminui o nível de carboidratos solúveis na planta. Como algumas etapas da fotossíntese são seriamente afetadas em condições de deficiência de Mn, outras reações associadas ao transporte de elétrons também 
o são, como a fotofosforilação, a redução de $\mathrm{CO}_{2}$, de nitrito e de sulfito (KIRKBY; RÖMHELD, 2007). Com o aumento das doses de manganês, era possível que ocorresse decréscimo na produção de massa seca da planta, devido ao seu efeito tóxico em quantidades excessivas. Porém, mesmo com a diminuição do acúmulo de alguns nutrientes, como $\mathrm{Mg}, \mathrm{Fe}$ e B, em função do incremento das doses de $\mathrm{Mn}$, a frutífera apresentou aumentos de massa seca em todas as estruturas, evidenciando sua tolerância ao elemento. Isso se deve, provavelmente, à rusticidade da planta, cujo centro de origem é tropical (Malásia ou Indonésia), onde os solos apresentam características de acidez e elevadas concentrações de Mn. Nesse ambiente, com a evolução, a planta deve ter desenvolvido mecanismos de adaptação e tolerância ao excesso de manganês.

Verificaram-se diferenças significativas em todos os parâmetros biológicos avaliados, em função da aplicação das doses de $\mathrm{Mn}$, com ajuste ao modelo quadrático. Esses resultados corroboram os de Veloso et al. (1995), para o crescimento de pimenteiras, o mesmo ocorrendo para as épocas de coleta, porém com ajuste linear (Tabela 3). A dose-padrão de Mn (0,5 $\mathrm{mg} \mathrm{L}^{-1}$ de $\left.\mathrm{Mn}\right)$ foi a que proporcionou as maiores médias de altura, diâmetro do porta-enxerto e do enxerto. Salvador et al. (2003), trabalhando com doses de manganês em mudas de goiabeira conduzidas em solução nutritiva, relataram que a concentração de $0,5 \mathrm{mg} \mathrm{L}^{-1}$ de $\mathrm{Mn}$ demonstrou ser a mais adequada para a frutífera naquela condição de estudo. Com relação às épocas de coleta, verificouse aumento linear da altura, do diâmetro do portaenxerto e do enxerto, em decorrência do crescimento natural das mudas de caramboleiras, concordando com os resultados relatados por Freitas (2008) e Rozane (2008), que trabalharam com mudas dessa frutífera cultivadas em hidroponia.

O incremento nos parâmetros biológicos pode ser explicado pelo crescente acúmulo da massa seca das folhas, caule e raízes, pois houve correlação positiva da massa seca total produzida pelas mudas de caramboleira, em decorrência da época de coleta, com a altura $\left(\mathrm{r}=0,99^{* *}\right)$, o diâmetro do porta-enxerto $\left(\mathrm{r}=0,99^{* *}\right)$, o diâmetro do enxerto $\left(\mathrm{r}=0,98^{* *}\right)$ e a área foliar $\left(r=0,99^{* *}\right)$. Isso pode ser explicado pelo rápido crescimento apresentado por plantas jovens dessa frutífera que, de acordo com Oliveira (1996), pode ser devido à sua grande capacidade de incorporação de $\mathrm{CO}_{2}$ (Tabela 3).

Houve diferenças significativas na eficiência de absorção, transporte e utilização de Mn pelas plantas, em função das doses de manganês empregadas. Ocorreu aumento linear na eficiência de absorção, com o incremento das doses $\left(\mathrm{y}=1.984,15+558,22 \mathrm{x} \mathrm{R}^{2}=\right.$ $\left.0,98^{* *}\right)$. Verificou-se decréscimo linear na eficiência de transporte $\left(\mathrm{y}=121,99-0,85 \mathrm{x} \mathrm{R}^{2}=0,45^{* *}\right)$ e, também, na eficiência de utilização ( $\mathrm{y}=300,71$ $6,77 \mathrm{x} \mathrm{R}^{2}=0,78^{* *}$ ) com a elevação das doses de manganês na solução nutritiva. A diminuição na eficiência de transporte e, também, de utilização do manganês pela caramboleira pode estar associada a um mecanismo de defesa da planta ao excesso de Mn presente na solução. Isso pode ser confirmado pelo maior acúmulo de manganês nas raízes, quando comparado às folhas e ao caule (Tabela 1). Os mecanismos de tolerância ao excesso de $\mathrm{Mn}$ têm sido associados à oxidação deste nutriente nas raízes, à restrição na taxa de absorção pelas raízes, à diminuição no transporte do excesso de $\mathrm{Mn}$ para as folhas, bem como à interação com outros nutrientes (FOY et al., 1988; MORONI et al., 2003). Além disso, pode ser possível que, a exemplo do que acontece com outros metais pesados, haja desintoxicação celular do excesso de manganês por agentes complexantes no sistema radicular (fitoquelatinas, metalotioneínas e nicotianamina), com posterior deposição do Mn no apoplasto, reduzindo seu transporte a longa distância e, por fim, estocagem no interior dos vacúolos (YAN et al., 2000; BIDWELL et al., 2002; DUCIC; POLLE, 2005). 
TABELA 1 - Resumo das análises de variância e resultados médios dos teores e acúmulo de manganês nas folhas, caule e raízes das mudas de caramboleiras, cultivadas em hidroponia, sob diferentes doses de manganês, e em função das épocas de coleta

\begin{tabular}{|c|c|c|c|c|c|c|}
\hline \multirow{2}{*}{ Doses de Mn (D) } & \multicolumn{3}{|c|}{ Teores de Mn } & \multicolumn{3}{|c|}{ Acúmulo de Mn } \\
\hline & Folhas & Caule & Raízes & Folhas & Caule & Raízes \\
\hline $\mathrm{mg} \mathrm{L}^{-1}$ & \multicolumn{3}{|c|}{--------- $\mathrm{mg} \mathrm{kg}^{-1}$--------- } & \multicolumn{3}{|c|}{------- $\mu \mathrm{g}$ planta $^{-1}$} \\
\hline 0 & 55 & 47 & 25 & 2.253 & 2.349 & 1.624 \\
\hline 0,5 & 74 & 52 & 67 & 3.311 & 2.875 & 4.411 \\
\hline 25 & 669 & 182 & 1.235 & 35.322 & 9.712 & 84.689 \\
\hline 50 & 1.443 & 406 & 1.471 & 79.875 & 22.333 & 103.077 \\
\hline Teste F & $863,89 * *$ & $828,11 * *$ & $491,56^{* *}$ & $656,13 * *$ & $595,14^{* *}$ & $585,07 * *$ \\
\hline \multicolumn{7}{|l|}{ Época Coleta (E) } \\
\hline 30 dias & 553 & 188 & 380 & 16.559 & 7.389 & 18.878 \\
\hline 60 dias & 555 & 172 & 615 & 24.967 & 7.888 & 41.093 \\
\hline 90 dias & 529 & 165 & 851 & 33.018 & 10.230 & 61.702 \\
\hline 120 dias & 604 & 163 & 951 & 46.219 & 11.761 & 72.129 \\
\hline Teste F & $2,01^{\mathrm{NS}}$ & $3,77^{*}$ & $55,36 * *$ & $78,45^{* *}$ & $28,81 * *$ & $115,56^{* *}$ \\
\hline $\mathrm{D} \times \mathrm{E}$ & $6,93 * *$ & $6,72 * *$ & $21,66 * *$ & $44,69 * *$ & $25,39 * *$ & $39,00 * *$ \\
\hline Doses d. 30 dias & $175,14 * *$ & $160,84 * *$ & $50,66 * *$ & $41,65 * *$ & $54,02 * *$ & $30,54 * *$ \\
\hline Doses d. 60 dias & $184,66^{* *}$ & $168,97 * *$ & $94,36^{* *}$ & $96,31 * *$ & $88,79 * *$ & $104,12^{* *}$ \\
\hline Doses d. 90 dias & $202,68 * *$ & $243,94 * *$ & $185,39 * *$ & $185,71 * *$ & $201,98 * *$ & $242,31 * *$ \\
\hline Doses d. 120 dias & $322,20 * *$ & $274,52 * *$ & $226,13^{* *}$ & $466,53^{* *}$ & $326,51 * *$ & $325,10^{* *}$ \\
\hline CV\% & 13,8 & 11,8 & 17,0 & 16,4 & 14,2 & 15,7 \\
\hline
\end{tabular}

$\mathrm{NS},{ }^{*},{ }^{* *}$ : não significativo $(p>0,05)$ e significativo a $p \leq 0,05$ e $p \leq 0,01$, respectivamente. 


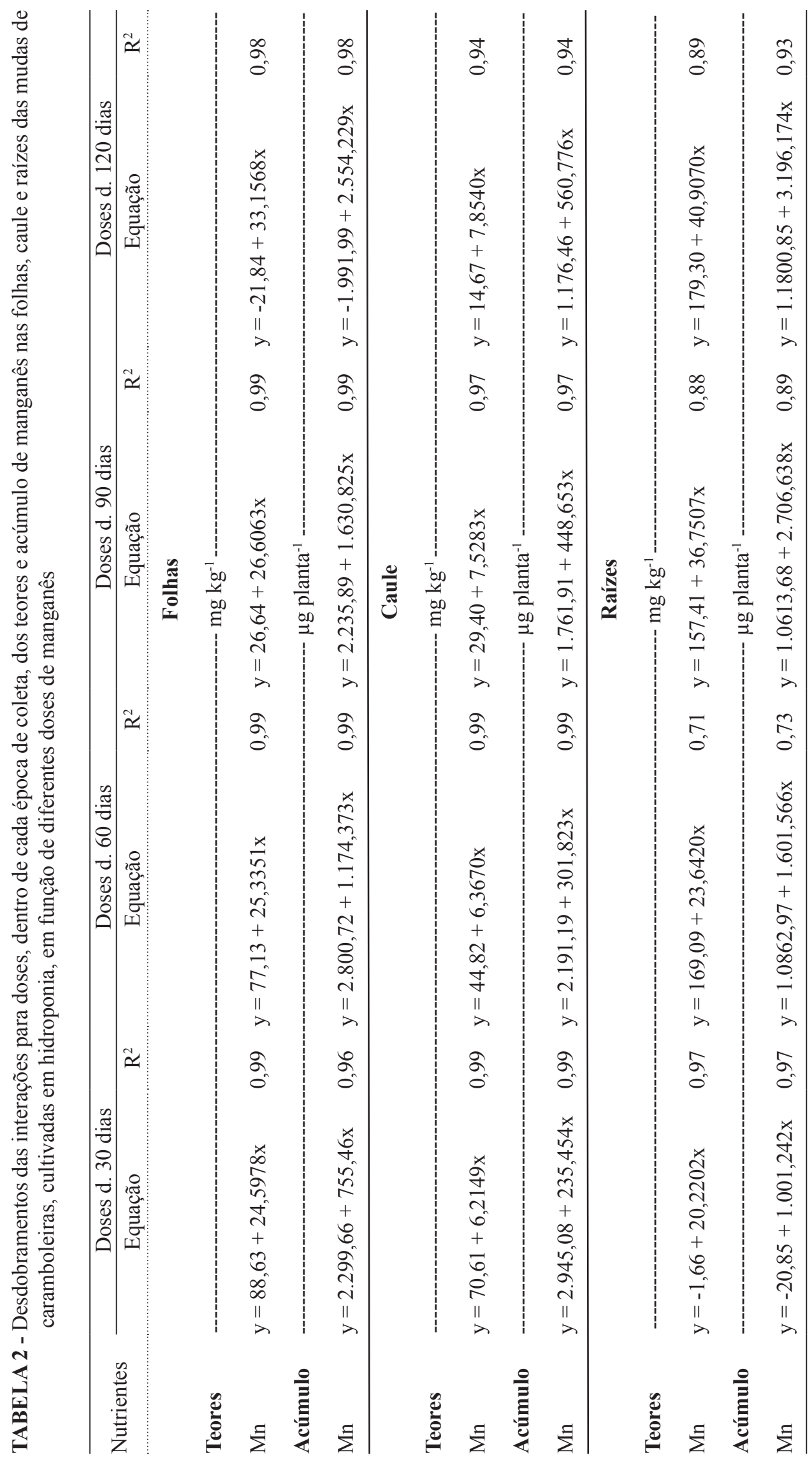


TABELA 3 - Resumo das análises de variância e resultados médios dos parâmetros biológicos das mudas de caramboleiras, cultivadas em hidroponia, sob diferentes doses de manganês

\begin{tabular}{|c|c|c|c|c|c|c|c|}
\hline \multirow{2}{*}{ Doses de Mn (D) } & \multirow{2}{*}{ Altura } & \multicolumn{2}{|c|}{ Diâmetro } & \multirow{2}{*}{ Área Foliar } & \multicolumn{3}{|c|}{ Massa Seca } \\
\hline & & Porta-Enxerto & Enxerto & & Folhas & Caule & Raízes \\
\hline$m g L^{-1}$ & $\mathrm{~cm}$ & \multicolumn{2}{|c|}{---------------mm------------- } & $\mathrm{cm}^{2}$ & \multicolumn{3}{|c|}{------------ g planta'-1 --------- } \\
\hline 0 & 126 & 9,6 & 6,1 & 2.462 & 46 & 53 & 64 \\
\hline 0,5 & 135 & 10,3 & 6,4 & 3.001 & 53 & 54 & 64 \\
\hline 25 & 130 & 9,6 & 6,1 & 2.719 & 53 & 56 & 65 \\
\hline 50 & 126 & 9,5 & 6,0 & 2.561 & 54 & 58 & 68 \\
\hline Teste F & $4,41 *$ & $7,31 * *$ & $4,23 *$ & $12,40 * *$ & $24,69 * *$ & $5,94 * *$ & $4,13 *$ \\
\hline Reg. Quadrática & $9,78 * 1$ & $7,33 * 2$ & $6,49 * 3$ & & & $15,89 * *$ & \\
\hline
\end{tabular}

Época Coleta $(\mathrm{E})$

\begin{tabular}{|c|c|c|c|c|c|c|c|c|}
\hline 30 dias & 115 & \multicolumn{2}{|l|}{8,5} & 5,0 & 1.519 & 31 & 40 & 51 \\
\hline 60 dias & 124 & \multicolumn{2}{|l|}{9,4} & 5,5 & 2.176 & 43 & 48 & 64 \\
\hline 90 dias & 135 & \multicolumn{2}{|l|}{10,3} & 6,3 & 3.150 & 59 & 59 & 70 \\
\hline 120 dias & 143 & \multicolumn{2}{|l|}{10,9} & 7,7 & 3.899 & 73 & 73 & 75 \\
\hline Teste F & $42,51 * *$ & \multicolumn{2}{|c|}{$58,53^{* *}$} & $153,08 * *$ & $246,86^{* *}$ & $550,62 * *$ & $335,12 * *$ & $135,98 * *$ \\
\hline Reg. Linear & \multicolumn{3}{|c|}{$127,25 * * 5174,85 * 6$} & \multicolumn{2}{|l|}{$432,10 * 7$} & & \multicolumn{2}{|l|}{$990,49 * * 8$} \\
\hline $\mathrm{D} \times \mathrm{E}$ & $1,68^{\mathrm{NS}}$ & \multicolumn{2}{|c|}{$0,90^{\mathrm{NS}}$} & $0,43^{\mathrm{NS}}$ & $4,54 * *$ & $10,66^{* *}$ & $1,84^{\mathrm{NS}}$ & $3,08 * *$ \\
\hline \multicolumn{4}{|c|}{ Doses d. 30 dias } & & $2,82^{\mathrm{NS}}$ & $5,68 * *$ & & $1,32^{\mathrm{NS}}$ \\
\hline \multicolumn{4}{|c|}{ Doses d. 60 dias } & & $0,57^{\mathrm{NS}}$ & $2,74^{\mathrm{NS}}$ & & $4,79 * *$ \\
\hline \multicolumn{4}{|c|}{ Doses d. 90 dias } & & $14,67 * *$ & $31,69 * *$ & & $4,40^{*}$ \\
\hline \multicolumn{4}{|c|}{ Doses d. 120 dias } & & $7,98 * *$ & $16,56^{* *}$ & & $2,88^{\mathrm{NS}}$ \\
\hline $\mathrm{CV} \%$ & 5,1 & 4,9 & & 5,4 & 8,6 & 5,3 & 4,9 & 4,8 \\
\hline \multicolumn{3}{|c|}{${ }^{1} \mathrm{y}=130+0,0704 \mathrm{x}-0,0032 \mathrm{x}^{2}$} & $\mathrm{R}^{2}=0,62$ & \multicolumn{2}{|c|}{${ }^{5} \mathrm{y}=105+0,3167 \mathrm{x}$} & \multicolumn{2}{|l|}{$\mathrm{R}^{2}=0,99$} & \\
\hline \multicolumn{3}{|c|}{${ }^{2} y=9,95-0,0154 x+0,00013 x^{2}$} & $\mathrm{R}^{2}=0,43$ & \multicolumn{2}{|c|}{${ }^{6} \mathrm{y}=7,74+0,02700 \mathrm{x}$} & \multicolumn{2}{|l|}{$\mathrm{R}^{2}=0,99$} & \\
\hline \multicolumn{3}{|c|}{${ }^{3} y=6,23-0,0068 x+0,00002 x^{2}$} & $\mathrm{R}^{2}=0,51$ & \multirow{2}{*}{\multicolumn{2}{|c|}{$\begin{aligned}{ }^{7} y & =3,92+0,02928 x \\
{ }^{8} y & =27,55+0,3679 x\end{aligned}$}} & $\mathrm{R}^{2}=0,94$ & & \\
\hline \multicolumn{3}{|c|}{${ }^{4} y=53,52+0,0915 x$} & $\mathrm{R}^{2}=0,97$ & & & $\mathrm{R}^{2}=0,99$ & & \\
\hline
\end{tabular}

$\mathrm{NS}, *{ }^{*},{ }^{*}$ : não significativo $(p>0,05)$ e significativo a $p \leq 0,05$ e $p \leq 0,01$, respectivamente. 


\section{CONCLUSÕES}

1-Há aumento linear nos teores e no acúmulo de Mn com o incremento das doses de manganês em todas as estruturas, independentemente da época de coleta. A massa seca das folhas, caule e raízes das mudas de caramboleiras aumenta com o incremento das doses de manganês e com o decorrer das épocas de coleta.

2-Ocorre aumento na eficiência de absorção de $\mathrm{Mn}$, bem como decréscimo na eficiência de transporte e de uso, em função do incremento das doses de manganês, o que pode indicar mecanismo de tolerância da planta ao elemento.

3-Os parâmetros biológicos avaliados (altura, diâmetro do porta-enxerto, diâmetro do enxerto e área foliar) apresentam as maiores médias na concentração de $0,5 \mathrm{mg} \mathrm{L}^{-1}$ de $\mathrm{Mn}$ na solução nutritiva.

\section{AGRADECIMENTOS}

Ao CNPq - Conselho Nacional de Desenvolvimento Científico e Tecnológico, pelo apoio financeiro concedido, através da concessão de Bolsa de Pós-Graduação (processo 136327/2008 7). Aos produtores Sr. José Mauro da Silva e Sr. João Mateus da Silva, do viveiro de mudas do Sítio São João - Taquaritinga, Estado de São Paulo, pelo fornecimento das mudas de caramboleira para a realização do presente estudo.

\section{REFERÊNCIAS}

BALERDI (s.d.). In: CRANE, J. H.; KNIGHT, J. R.; RODRIGUEZ, O.; CRANE, L. C. Cultivar tree growth and content a good quality index? HortScience, Alexandria, v.9, p.136-137, 1998.

BATAGLIA, O. C.; FURLANI, A. M. C.; TEIXEIRA, J. P. F.; FURLANI, P. R.; GALLO, J. R. Métodos de análise química de plantas. Campinas: Instituto Agronômico, 1983. 48p. (Boletim Técnico, 78).

BIDWELL, S. D.; WOODROW, I. E.; BATIANOFF, G. N.; SOMMER-KNUDSEN, J. Hyperaccumulation of manganese in the rainforest tree Austromystus bidwillii (Mirtaceae) from Queensland, Australia. Functional Plant Biology, Victoria, v. 29, p. 899905, 2002.
BURNELL, J. N. The biochemistry of manganese in plants. In: GRAHAM, R. D.; HANNAM, R. J.; UREN, N. C. Manganese in soils and plants. Dordrecht: Kluwer Academic Publishers, 1988. p.125-137.

CRANE, J. H. Tropical fruits.Gainsville: Institute of Food and Agricultural Science, University of Florida, 1998, v.1. CD-ROM.

DECHEN, A. R.; NACHTIGALL, G. R. Micronutrientes. In: FERNANDES, M. S. Nutrição mineral de plantas. Viçosa-MG: Sociedade Brasileira de Ciência do Solo, 2006. 432 p.

DUCIC, T.; POLLE, A. Transport and detoxification of manganese and copper in plants. Brazilian Journal of Plant Physiology, Brasília, v.17, p.103-112, 2005.

EPSTEIN, E.; BLOOM, A. J. Nutrição mineral de plantas: princípios e perspectivas. 2. ed. Londrina: Editora Planta, 2006. 403 p.

ESTAT: Sistema para análises estatísticas (v.2.0). Jaboticabal: Departamento de Ciências Exatas, UNESP, Câmpus Jaboticabal, 1992.

FOY, C.D. Manganese and plants. In: FOY, C.D. Manganese. Washington: National Academy of Sciences, 1973. p.51-76.

FOY, C. D. Physiological effects of hydrogen, aluminum, and manganese toxicities in acid soil. In: ADAMS, F. (Ed.). Soil acid and liming. Madison: American Society of Agronomy, 1984. p.57-98.

FOY, C. D.; CHANEY, R. L.; WHITE, M. C. The physiology of metal toxicity in plants. Annual Review of Plant Physiology, Lancaster, v.29, p.511566,1978

FOY, C. D.; SCOTT, B. J.; FISHER, J. A. Genetics and breeding of plant of manganese toxicity. In: GRAHAM, R. D.; HANNAM, R J.; UREN, N. C. eds. Manganese in soils and plants. Dordrecht: Kluwer Academic Publishers, 1988. p. 293-307.

FREITAS, N. Curva de crescimento e marcha de absorção de nutrientes em mudas de caramboleiras 'Nota-10'. 2008. 81 f. Monografia (Trabalho de graduação em Agronomia) - Faculdade de Ciências Agrárias e Veterinárias, Universidade Estadual Paulista, Jaboticabal, 2008. 
FURLANI, P. R. Hydroponic vegetable production in Brazil. Acta Horticulturae, Wageningen, v.2, n. 481, p.777-778, 1999.

GRAHAM, R. D. Effect of nutrient stress on susceptibility of plants to disease with particular reference to the trace elements. Advances in Botanical Research, London, v.10, p.221-276, 1983.

GRAHAM, R. D.; WEBB, M. J. Micronutrients and disease resistance and tolerance in plants. In: MORTVEDT, J. J.; COX, F. R.; SHUMAN, L. M.; WELCH, R. M. (Ed.). Micronutrients in Agriculture. Soil Science Society of America, Madison, p.333-339, 1991.

KIRKBY, E. A.; RÖMHELD, V. Micronutrientes na fisiologia de plantas: funções, absorção e mobilidade. Informações Agronômicas, Piracicaba, $n^{\circ} 118$, p.1-3, 2007.

LEAL, R. M. Adubação nitrogenada da caramboleira para pomar em implantação. 2006. 53 f. Tese (Doutorado em Agronomia) - Faculdade de Ciências Agrárias e Veterinárias, Universidade Estadual Paulista, Jaboticabal, 2006.

LEE, C. R. Interrelationships o aluminum and manganese on the potato plant. Agronomy Journal, Madison, v.64, p.546-549, 1972.

LI, B.; McKEAND, S. E.; ALLEN, H. L. Genetic variation in nitrogen use efficiency of loblolly pine seedlings. Forest Science, Bethesda, v.37, nº 2, p.613-626, 1991.

LINDSAY, C. C.; ROSS, O. N. Physiological functions of manganese in plants. In: GRAHAN, R. D.; HANNAM, R. J.; UREN, N. C. (Ed.). Manganese in soils and plants. Dordrecht: Kluwer Academic, 1988. p.139-154.

LUCENA, J. J.; GARATE, A.; CARPENA, O. Theoretical and practical studies on chelate $\mathrm{Ca}$-pH system in solution. Journal of Plant Nutrition, New York, v. 11, p. 1051-1062, 1988.

MALAVOLTA, E. Manual de nutrição mineral de plantas. São Paulo: Agronômica Ceres, 2006. 638p. MALAVOLTA, E.; KLIEMANN, H. J. Desordens nutricionais no cerrado. Piracicaba: Potafós, 1985. $136 \mathrm{p}$.
MALAVOLTA, E.; SANTOS, J. F. C. Efficiency of the use of nutrients in acid soils - management of soil, fertilizer and crop. Piracicaba: CENA,USP, 1996. 110 p.

MALAVOLTA, E.; VITTI, G. C.; OLIVEIRA, S. A de. Avaliação do estado nutricional das plantas: princípios e aplicações. 2.ed. Piracicaba: Potafós, 1997. 319p.

MARSCHNER, H. Mineral nutrition of higher plants. London: Academic, 1995. 889 p.

MORONI, J. S.; SCOTT, B. J.; WRATTEN, N. Differential tolerance of high manganese among rapeseed genotypes. Plant and Soil, Dordrecht, v. 253, p. 507-519, 2003.

OLIVEIRA, M. N. S. Comportamento fisiológico de plantas jovens de acerola, carambola, pitanga, cupuaçu, graviola, pupunha e biriba, em função da baixa disponibilidade de água no solo. 1996. 67f. Lavras: Dissertação (Mestrado) - Escola Superior de Agricultura de Lavras, Lavras. 1996.

PAVAN, M. A.; BINGHAM, F. T. Toxidez de metais em plantas. I. Caracterização de toxidez de manganês em cafeeiros. Pesquisa Agropecuária Brasileira, Brasília, v.16, nº 6 , p25-821, 1981.

PRADO, R. M. Efeitos da calagem no desenvolvimento, no estado nutricional e na produção de frutos da goiabeira e da caramboleira. 2003. $68 \mathrm{f}$. Tese (Doutorado em Agronomia) - Faculdade de Ciências Agrárias e Veterinárias, Universidade Estadual Paulista, Jaboticabal, 2003.

PRADO, R. M.; NATALE, W. Effect of Liming on the Mineral Nutrition and Yield of Growing Guava Trees in a Typic Hapludox Soil. Communications in Soil Science and Plant Analysis, Philadelphia, v.39, p.2191-2204, 2008.

ROZANE, D. E. Crescimento e acúmulo de nutrientes em caramboleiras nas fases de hipobioto, muda e plantas em formação. 2008. $161 \mathrm{f}$. Tese (Doutorado em Agronomia) - Faculdade de Ciências Agrárias e Veterinárias - Universidade Estadual Paulista, Jaboticabal, 2008. 
ROZANE, D. E.; PRADO, R. M.; FRANCO, C. F.; NATALE, W. Eficiência de absorção, transporte e utilização de macronutrientes por porta-enxertos de caramboleira, cultivados em soluções nutritivas. Ciência e Agrotecnologia, Lavras, v.31, n.4, p.10201026, 2007.

SALVADOR, J. O.; MOREIRA, A.; MALAVOLTA, E.; CABRAL, C. P. Influência do boro e do manganês no crescimento e na composição mineral de mudas de goiabeira. Ciência e Agrotecnologia, Lavras, v.27, n.2, p.325-331, 2003

SAÚCO, V. G. Possibilities of no-citrus tropical fruit in the Mediterranean. Acta Horticulturae, Hague, n.365, p.25-41, 1994.

SIDDIQI, M. Y.; GLASS, A. D. M. Utilization index: a modified approach to the estimation and comparison of nutrient efficiency in plants. Journal of Plant Nutrition, Monticello, v.4, n.3, p.289-302, 1981.
SILVA, H.; SILVA, A. Q.; CAVALCANTI, A. T.; MALAVOLTA, E. Composição mineral das folhas de algumas fruteiras do Nordeste. In: CONGRESSO BRASILEIRO DE FRUTICULTURA, 7., 1984, Florianópolis. Anais... Florianópolis: EMPASC/SBF, 1984. v.1, p.320-325.

SWIADER, J. M.; CHYAN, Y.; FREIJI, F. G. Genotypic differences in nitrate uptake and utilization efficiency in pumpkin hybrids. Journal of Plant Nutrition, Monticello, v.17, n.10, p.1687 - 1699, 1994.

VELOSO, C.A. C.; MURAOKA, T.; MALAVOLTA, E.; CARVALHO, J. G. de. Influência do manganês sobre a nutrição mineral e crescimento da pimenteira do reino. Scientia Agricola, Piracicaba, v.52, n.2, p.376-383, 1995.

YAN, S. L.; TSAY, C. C.; CHEN, Y. R. Isolation and characterization of phytochelatin synthase in rice seedlings. Proceedings of the National Science, Republic Taipei, v.24, p.202-207, 2000. 